\title{
En bloc resection of a C-1 lateral mass osteosarcoma: technical note
}

\author{
Michelle J. Clarke, MD, ${ }^{1}$ Daniel L. Price, MD, ${ }^{2}$ Harry J. Cloft, MD, PhD, ${ }^{3}$ Leal G. Segura, MD, ${ }^{4}$ \\ Cindy A. Hill, CST, ${ }^{1}$ Meghen B. Browning, MD, ${ }^{5}$ Jon M. Brandt, MD, ${ }^{6}$ Sean M. Lew, MD, ${ }^{7}$ and \\ Andrew B. Foy, MD'
}

\begin{abstract}
Departments of ${ }^{1}$ Neurologic Surgery, ${ }^{2}$ Otorhinolaryngology, ${ }^{3}$ Radiology, and ${ }^{4}$ Anesthesiology, Mayo Clinic, Rochester, Minnesota; ${ }^{5}$ Department of Pediatric Oncology, Medical College of Wisconsin, Milwaukee; ${ }^{6}$ Department of Pediatric Oncology, St. Vincent Hospital, Green Bay; and 'Department of Pediatric Neurosurgery, Medical College of Wisconsin, Milwaukee, Wisconsin
\end{abstract}

\begin{abstract}
Osteosarcoma is an aggressive primary bone tumor. It is currently treated with multimodality therapy including en bloc resection, which has been demonstrated to confer a survival benefit over intralesional resection. The authors present the case of an 8-year-old girl with a C-1 lateral mass osteosarcoma, which was treated with a 4-stage en bloc resection and spinal reconstruction. While technically complex, the feasibility of en bloc resection for spinal osteosarcoma should be explored in the pediatric population.
\end{abstract}

http://thejns.org/doi/abs/10.3171/2015.12.PEDS15496

KEY WORDS en bloc resection; primary tumor; osteosarcoma; neoadjuvant chemotherapy; transoral odontoidectomy; oncology

$\mathrm{O}$ STEOSARCOMA is an aggressive primary bone tumor with a poor overall prognosis..$^{23,37,39}$ Currently, multimodality therapy is recommended and includes adjuvant and neoadjuvant chemotherapy and surgery., 2,14,16,40 Based on data from studies of osteosarcoma involving the appendicular bones,,$^{21,27,28,36}$ a survival advantage is conferred by wide-margin resections. Additionally, en bloc resection of extraspinal osteosarcoma, whereby the tumor is removed in one piece with negative margins, has been demonstrated to provide improved local control and long-term survival over tumors treated with intralesional resection. $6,13,15,17,22,24,29,35,38$ However, due to the proximity of critical structures to the spine, only recently have spinal osteosarcomas been treated surgically using en bloc resections. While descriptions of this technique have been limited to case reports and small case series, en bloc resection of spinal osteosarcomas appears to confer a survival benefit. ${ }^{1,3,4,18,20,25,26,41}$

We describe the case of an 8-year-old girl with a C-1 lateral mass osteosarcoma whose treatment involved two major issues of surgical feasibility. First, this patient is one of the youngest known to have undergone an en bloc resection of a spinal tumor. Second, the case illustrates the technical challenges of a C-1 lateral mass lesion requiring a multistage approach. The procedure is described and both issues explored.

\section{Technical Note}

Presentation, Diagnosis, and Neoadjuvant Chemotherapy

The patient was an 8-year-old girl who was asymptomatic until a fall, whereupon she complained of upper cervical pain. Radiographs revealed a lytic abnormality in $\mathrm{C}-1$, and subsequent imaging revealed a $\mathrm{C}-1$ right lateral mass lesion and pathological fracture (Fig. 1). Metastatic workup was negative. Transoral biopsy of the mass established a diagnosis of giant cell osteosarcoma. The patient underwent 2 full cycles, and a portion of a third, of neoadjuvant high-dose chemotherapy consisting of doxorubicin, cisplatin, and methotrexate prior to operative intervention. Upon presentation for surgery, the patient weighed $23 \mathrm{~kg}$ and was otherwise healthy. Following an extensive discus- 

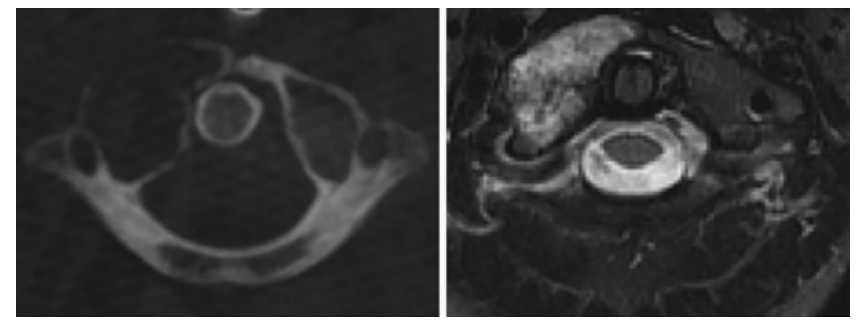

FIG. 1. CT scan (left) and T2-weighted MR image (right) demonstrating the right lateral mass osteosarcoma.

sion with her parents, the family elected to pursue an en bloc resection. The patient underwent restaging of the tumor with MRI and PET, which again confirmed the C-1 lateral mass as the only site of disease.

\section{Stage 1: Right Vertebral Artery Embolization}

As the right vertebral artery was immediately adjacent to the tumor, preoperative endovascular occlusion for vessel sacrifice was performed. With the patient positioned supine and after induction of general anesthesia, a standard 4-vessel cerebral angiogram confirmed a normal circle of Willis. The right vertebral artery was catheterized, and a test balloon occlusion was performed without issue. Multiple endovascular coils were placed, extending from proximal to the $\mathrm{C}-1$ vertebra to the $\mathrm{C} 2-3$ disc (Fig. 2). A segment of the horizontal vertebral artery was left uncoiled over the $\mathrm{C}-1$ arch as the posterior inferior cerebellar artery (PICA) branched off immediately after the vertebral artery entered the dura, and it was thought that surgical manipulation of more proximal coils could result in intracranial bleeding or PICA stroke. Postoperative angiography demonstrated occlusion of the vertebral artery. The patient was neurologically well and transferred to the pediatric intensive care unit for monitoring overnight.

\section{Stage 2: Posterior Approach and Instrumentation}

The following day the patient underwent a posterior cervical approach to maximally dissect the margins of the lateral mass lesion and to place instrumentation for stabilization, temporary distraction, and eventual permanent spinal column reconstruction (Fig. 3). Under general anesthesia, the patient was positioned prone on a padded Jackson table using a Mayfield head holder. Somatosensory and motor evoked potential (SSEP and MEP) monitoring, used throughout the case, showed no signal changes.

A standard midline posterior cervical approach was

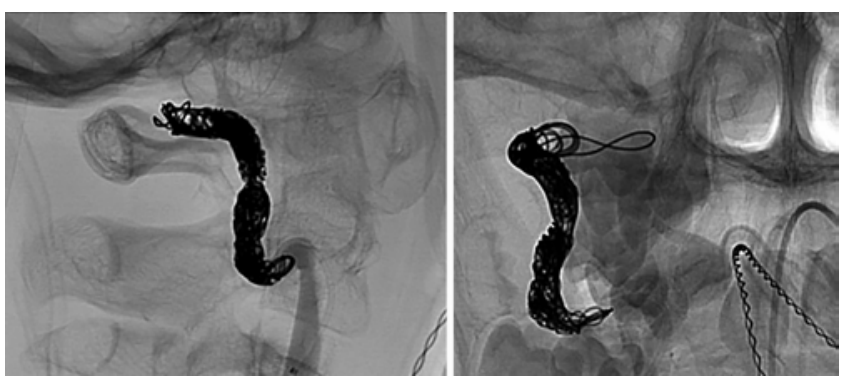

FIG. 2. Lateral (left) and AP (right) radiographs of the endovascularly coiled right vertebral artery.

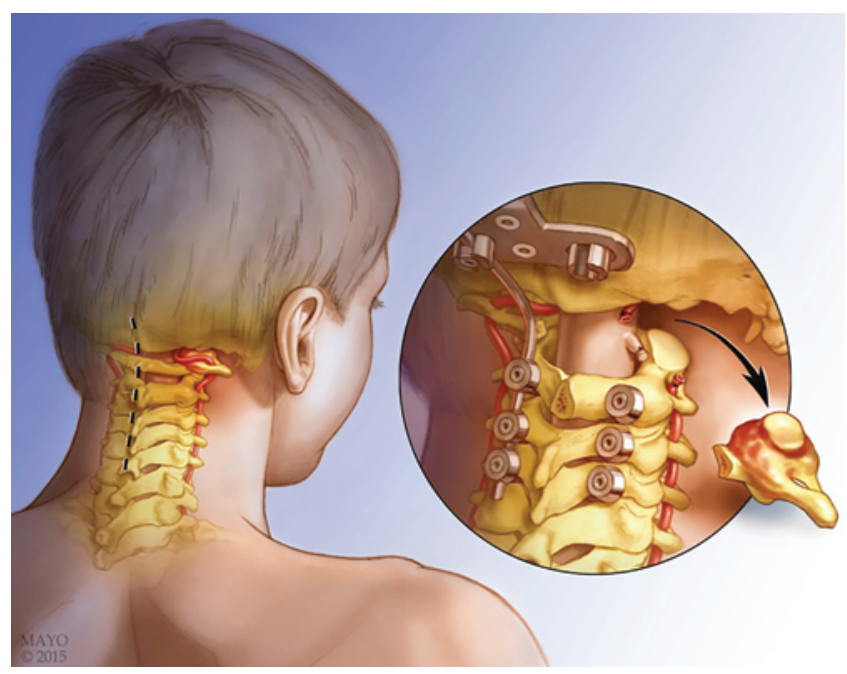

FIG. 3. Artistic interpretation of lateral mass tumor, posterior instrumentation, and trajectory of tumor removal. Used with permission of Mayo Foundation for Medical Education and Research; all rights reserved.

performed to expose the area from the occiput to C-4, although the right $\mathrm{C}-1$ region was left undissected to avoid breaching the tumor. A narrow C-1 laminectomy was performed to preserve the left vertebral artery and avoid disrupting the right-sided tumor. The $\mathrm{C}-2$ spinous process was removed to create a larger working space. The C-2 nerve roots were sacrificed bilaterally, exposing the $\mathrm{C} 1-2$ joints. To avoid inadvertently spilling tumor cells at C-1, this dissection was performed mainly over C-2. Upon completion, the coiled right vertebral artery was exposed and a portion resected to provide access to the lateral side of $\mathrm{C}-1$ and C-2. An O-arm/StealthStation (Medtronic) navigational spin was performed to aid dissection and instrumentation placement.

The lateral, anterolateral, and superior borders of the mass were defined. Working around the lateral side of the vertebral body of $\mathrm{C}-2$ to avoid disrupting the $\mathrm{C}-1$ tumor, the superior edge of the $\mathrm{C}-2$ lateral mass was demarcated. Working superiorly along the lateral border of C-1, the top of the $\mathrm{C}-1$ arch was defined. The remaining coiled vertebral artery was carefully dissected and severed directly through the coils. This allowed dissection of the occipital condyle and the occipitocervical joint. Dissection continued anteriorly, defining the jugular vein, vagus nerve, and carotid artery (Fig. 4). Ultimately, it was possible to pass an instrument approximately $1 \mathrm{~cm}$ medial to the carotid artery from the $\mathrm{C} 2-3$ joint to the occipital condyles without any soft-tissue encumbrance.

Subsequently, the medial border of the tumor and the dens were defined. Using the stub of the C-2 nerve root and a small brain spatula, the dura was retracted medially at the $\mathrm{C} 1-2$ space. Following the lateral mass of C-2 medially, the dens was demarcated using pinpoint cautery from the shoulder of the lateral mass to the tip of the dens above the level of the C-1 arch. No tumor was encountered at any point. A Silastic membrane was placed anterior to the C-1 lateral mass to prevent any scarring of the tissue into the dissection plane and also to serve as a landmark for the anterior approach. 
Attention was then turned to instrumentation (MOUNTAINEER, DePuy Synthes). Lateral mass screws were placed at C-3 and C-4 bilaterally using the Magerl technique. Pedicle screws were placed at $\mathrm{C}-2$ bilaterally using direct visualization and computer-assisted navigation. Of note, due to the sacrifice of the right vertebral artery, care was taken to avoid breaching tumor on the right or injuring the vertebral artery on the left. A left C-1 lateral mass screw was placed in standard fashion. A small occipital plate was secured to the occipital bone. Rods were contoured and final tightened into the occipital plate while the rods were seated more loosely in the saddles of the remaining screws. To open the occipital C-1 and C1-2 joints to aid dissection and tumor removal in later stages, the rod was distracted between the occipital plate and C-2. A distractor was also placed between the remaining solid arch of C-1 and the occiput. This provided over $2 \mathrm{~mm}$ of distraction of both the occipital cervical joints and the $\mathrm{C} 1-2$ joints, and the rod was final tightened in this open position. A second small Silastic sheet was placed between the spinal cord and the dens/C-1 lateral mass to preserve our resection and provide guidance during the anterior stage (Fig. 5).

Following closure, the patient was positioned supine on a standard operating table to determine whether the transoral approach would provide adequate exposure for the third stage. A McIvor mouth gag was placed, and, using a pedicle probe and fluoroscopy, we ensured that the osteotomy cuts and dissection required were achievable from a transoral approach.

Due to the patient's relatively small size and preoperative hemoglobin level of $8.5 \mathrm{~g} / \mathrm{dl}$, she was given a blood transfusion before incision. A great deal of attention was paid to hemostasis during the procedures, and less than $100 \mathrm{ml}$ of blood was lost during this stage. The patient was then awakened, extubated, and taken directly to the intensive care unit neurologically intact. Prior to the next stage of the procedure, a Stealth CT scan was performed to assist in surgical navigation and assess the previous stage's dissection and instrumentation.

\section{Stage 3: Transoral Approach and C-1 Anterior Arch Osteotomy}

The transoral approach was chosen to perform the C-1 anterior arch osteotomy and anterior dissection as it afforded the opportunity to resect the transoral biopsy tract, which was an area of potential tumor contamination (Fig. 6). After discussion involving the anesthesia, otorhinolaryngology, and neurosurgical teams, it was decided that the best management of the patient's airway would be to perform a tracheostomy. The patient was brought to the operating room and underwent an uncomplicated endotracheal intubation, and a tracheostomy was performed in a vertical fashion through approximately the third tracheal ring using a 5-0 cuffed Bivona tracheostomy tube (Smiths Medical). The oral cavity was exposed with a McIvor mouth gag, red rubber catheters were placed through the nose to elevate the palate, and a stitch was placed through the uvula. The posterior pharyngeal wall was injected with $3 \mathrm{ml}$ of $0.5 \%$ bupivacaine with 1:100,000 epinephrine and subsequently incised using electrocautery. Scar tissue in the posterior pharynx, thought to be the original

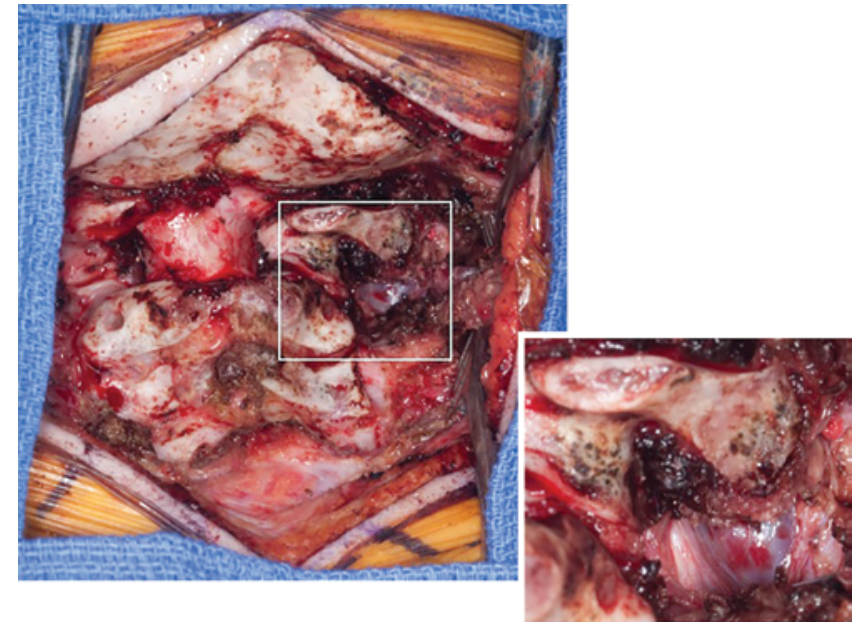

FIG. 4. Photographs obtained following the posterior approach, C-1 laminectomy, and vertebral artery resection. Visible in the small box is the jugular vein anterior to the $\mathrm{C}-1$ and $\mathrm{C}-2$ lateral masses.

biopsy tract, was excised. Intraoperative pathological examination revealed scar tissue but no tumor cells. Due to the length of time between biopsy and surgery, it is unclear if the biopsy tract was truly resected.

The anterior dissection was then completed. The longus colli muscle was identified and left intact over C-1. Using Stealth guidance, the upper and lower borders of C-1 and the medial border of the osteosarcoma were identified. Dissection was carried through the prevertebral fascia and longus colli muscle in a paramedian position to the arch of C-1 (Fig. 7). Of note, this patient was young enough that the cartilaginous bridge between the ossification centers of C-1 remained intact and acted as a biological barrier to tumor progression. As the left side of the anterior arch was free of tumor, the goal was to remove the

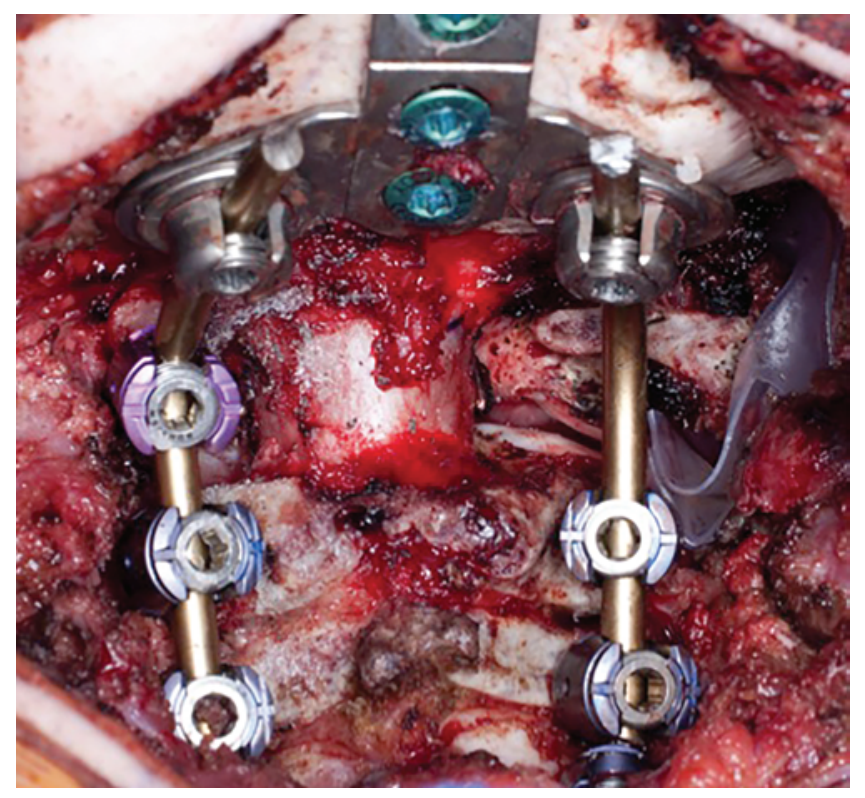

FIG. 5. Intraoperative photograph showing posterior instrumentation in place at the completion of Stage 2. Note the Silastic sheet demarcating the dissection planes and the distracted C1-2. 


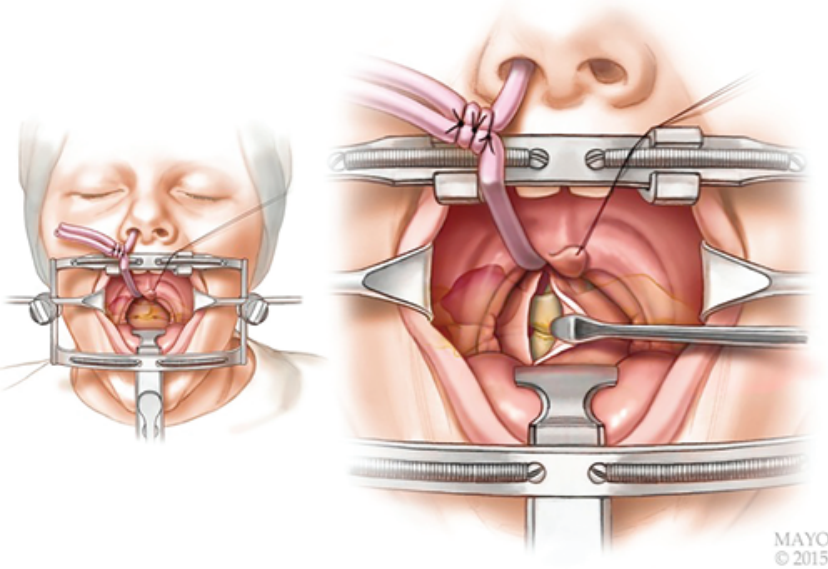

FIG. 6. Artistic interpretation of the transoral approach. Elevator retraction exposes the relationship of $\mathrm{C}-1$ and $\mathrm{C}-2$ to the incision. Used with permission of Mayo Foundation for Medical Education and Research; all rights reserved.

cartilaginous bridge with the tumor to achieve a negative margin. The interspace between the occipital condyles in C-1 and the C1-2 interspace were dissected. The dissection was then carried laterally to the carotid sheath, which was confirmed using Doppler ultrasound. Working posteriorly, we identified the Silastic sheet, which had been placed during Stage 2. Finally, dissection was completed superiorly and inferiorly, and the longus colli muscle overlying the tumor was divided and maintained as a margin. An osteotomy of the arch of C-1, approximately $4 \mathrm{~mm}$ lateral on the left side beyond the cartilaginous bridge to the tumor, was completed, mobilizing $\mathrm{C}-1$. The ligament attachments superiorly and inferiorly were divided with cautery, at which point a small dural breach just inferior to the foramen magnum was noted and subsequently closed with a local muscle pledget. Having fully mobilized the C-1 lateral mass, the pharyngotomy was closed with horizontal mattress sutures and the retractors removed.

\section{Stage 4: Posterior Tumor Removal and Spinal Column Reconstruction}

The patient was immediately placed prone on a Jackson table and prepared as in Stage 2. The previous incision was reopened and the right-sided rod removed from the construct. As the C-1 tumor had been freed in all dimensions, it was gently rocked and separated from the occipitocervical and $\mathrm{Cl}-2$ joint capsules. Once the mass was completely loose, it slid sideways and rotated out in one piece. Examining the mass, there was no evidence of violation of the tumor. Pathological examination confirmed negative tumor margins.

Attention was turned to reconstruction. The shoulder of the C-2 articular process was squared and a decorticated docking site on the occipital condyle created. An allograft fibular strut was then sized carefully and contoured to fit both docking sites. ${ }^{11}$ This was press-fitted into place. The contralateral rod was loosened to ensure an excellent arthrodesis from the occipital bone to $\mathrm{C}-4$ bilaterally using a femoral head allograft. ${ }^{7}$ Rods were replaced, and the occipital C-2 region was compressed bilaterally, locking the

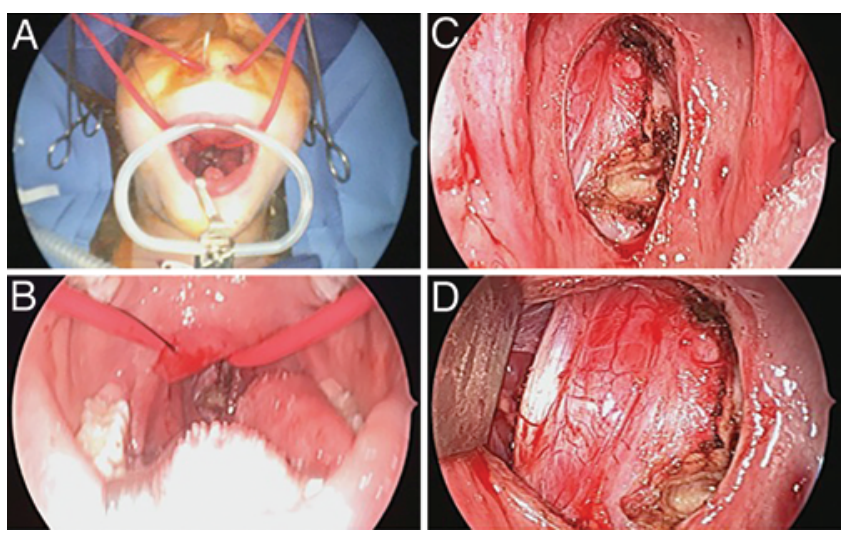

FIG. 7. Endoscopic view of surgical exposure (A), retraction with red rubber catheter (B), and the posterior pharyngeal incision, longus coli muscles, and anterior spinal column (C and D).

fibular strut into place (Figs. 8 and 9). Via the posterior approach, we visualized the pharyngeal closure and placed DuraSeal (Covidien) in the region of the durotomy. All screws were final tightened, and the incision was closed in tight layers. Following the procedure, the patient was turned on her side, and a lumbar drain was placed. The patient was then placed supine and a feeding tube was inserted. The patient was awakened and taken to the intensive care unit.

\section{Postoperative Course and Follow-Up}

The patient did very well postoperatively. Pathological examination of the tumor confirmed the diagnosis of osteosarcoma (Fig. 10). The patient was mobilized in a cervical collar the day after surgery. Her tracheostomy was removed on postoperative Day 2 along with the lumbar drain. A small pharyngeal pouch was noted and oral intake was restricted. This ultimately required surgical revision 6 weeks following resection and has since been without issue. The patient did have a temporary gastrostomy tube placed, because of the pharyngeal pouch and because of poor oral intake while wearing the cervical collar. The

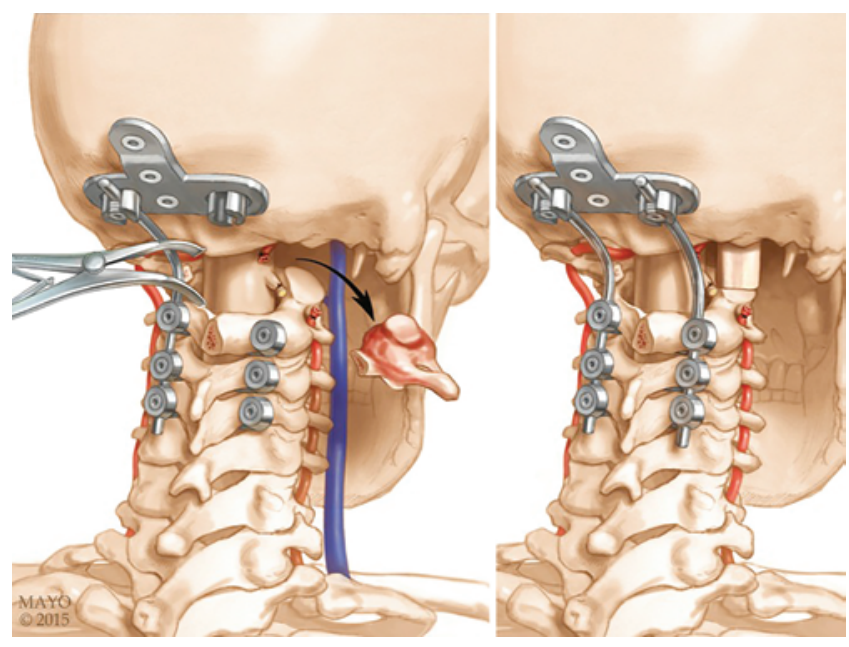

FIG. 8. Artistic interpretation of posterior instrumentation distraction, facilitating tumor removal (note blue jugular vein) and final reconstruction with bone strut. Used with permission of Mayo Foundation for Medical Education and Research; all rights reserved. 


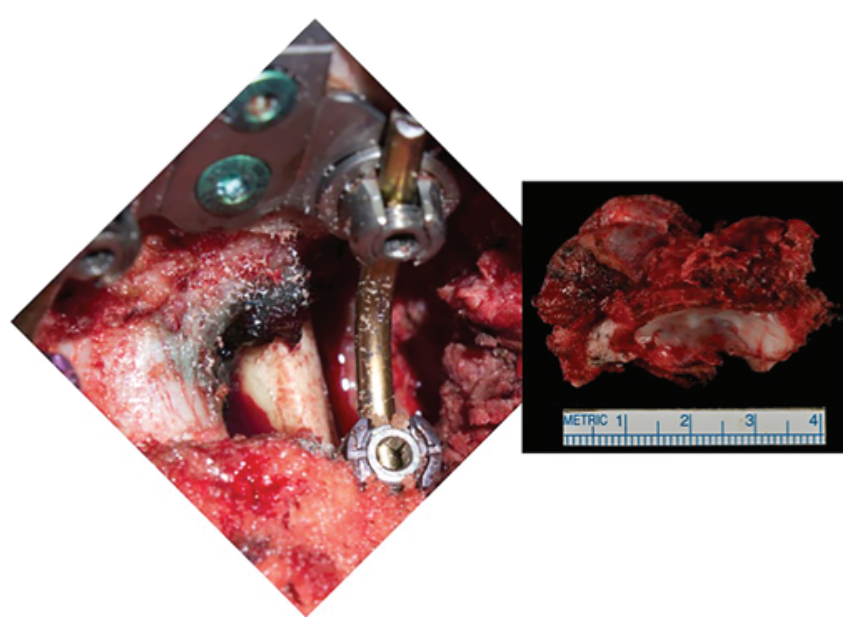

FIG. 9. Photographs of posterior reconstruction (left) and final pathology specimen (right).

patient completed further chemotherapy according to the standard arm of the COG AOST0331 protocol. At the 3-month follow-up, excellent bone healing (Fig. 11) was seen and the cervical collar was removed. A CT scan at 5.5 months demonstrated complete fusion of the construct (Fig. 12), although we continued serial follow-up radiography every 6 months in addition to tumor surveillance imaging. At the 16-month mark postoperatively, there was no evidence of disease. The patient will continue standard tumor surveillance.

\section{Discussion}

En bloc resection involves removing a tumor in one unviolated piece as opposed to its foil, the intralesional resection. While en bloc resection of an osteosarcoma is the preferred treatment, technical challenges in the spine make this difficult due to the proximity of critical structures. Tomita et al. first described en bloc resection of a spinal lesion in $1994 .{ }^{43}$ Since then, Tomita's technique has been applied throughout the fixed and mobile spine. ${ }^{8-10,12,33,34,42,44}$ However, en bloc resections in the high cervical spine have

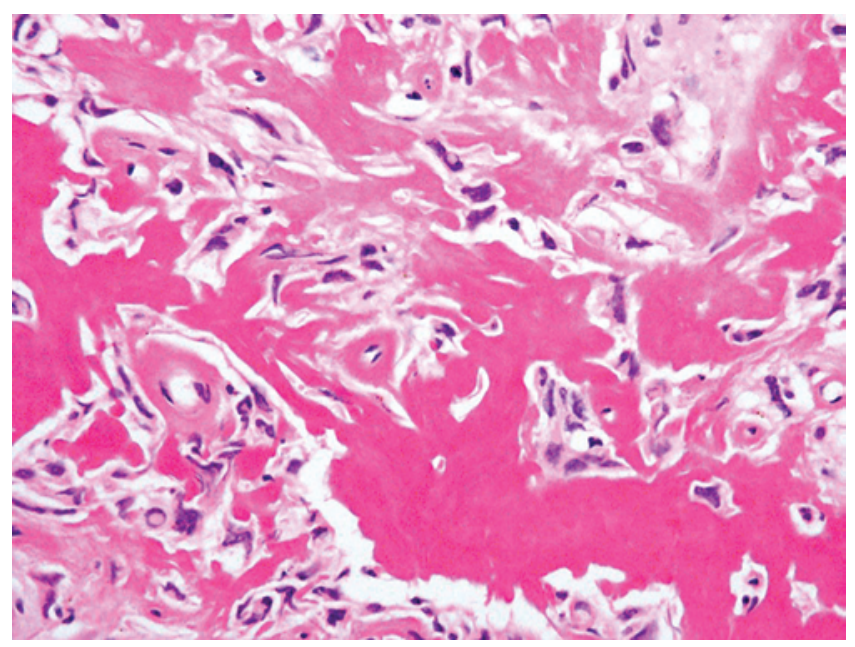

FIG. 10. H \& E-stained photomicrograph confirming osteosarcoma diagnosis. Original magnification $\times 400$.

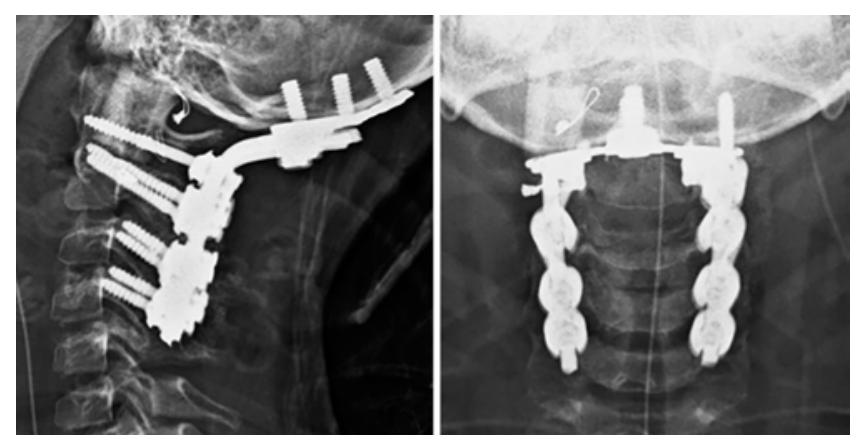

FIG. 11. Follow-up lateral (left) and AP (right) radiographs acquired at 3 months.

proven particularly formidable. Although the upper cervical nerve roots can generally be sacrificed without causing neurological deficit, the vertebral arteries, pharynx, cranial nerves, spinal cord, and brainstem are far less forgiving. Additionally, complex surgical approaches, such as a submandibular or transmandibular approach, posterior pharyngeal incisions, and far-lateral cervical approaches, and the need for a tracheostomy or feeding tube diminish the enthusiasm for attempting these relatively morbid procedures.

To date, the largest series of high cervical en bloc re-

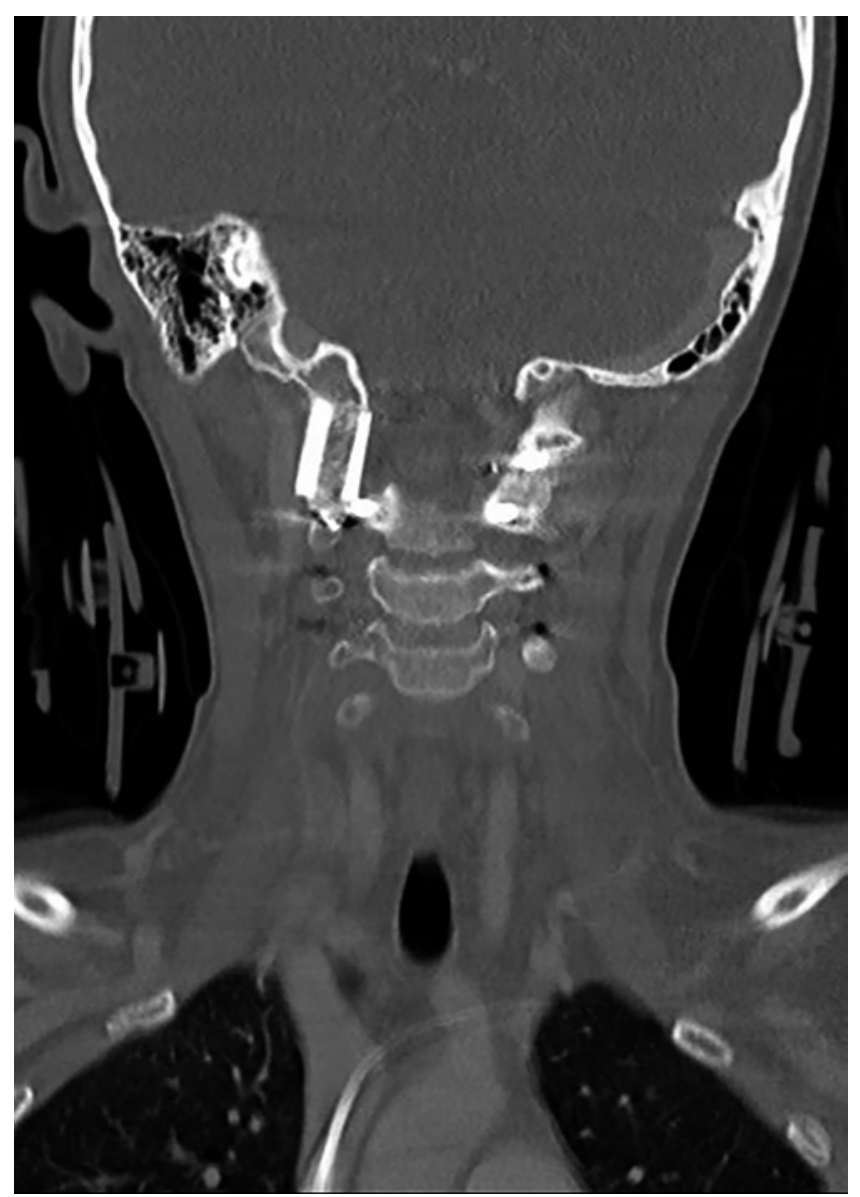

FIG. 12. Follow-up coronal CT scan at obtained 5.5 months demonstrating incorporation of the fibular strut. In this CT series, all sites demonstrated solid fusion. 
sections bears out these concerns. ${ }^{30}$ In a multiinstitutional study of 16 patients in whom $\mathrm{C} 1-2$ en bloc resections for chordoma were attempted, the likelihood of achieving the desired marginal margins was only $29 \%$ in contrast to a rate of $79 \%$ in a control population in which subaxial en bloc resections were attempted. Although the survival rate was not significantly different between the groups, there was a significantly higher rate of local and distant recurrence in the patients who underwent high cervical resections. While this finding underscores the difficulty of achieving clean margins, this study also noted a significantly higher rate of postoperative complications in those undergoing high cervical resection compared with those undergoing subaxial resection $(71 \%$ vs $22 \%$, respectively). Complications of the pharyngeal incision including dehiscence and dysphagia were most commonly reported. Indeed, this profile fits our patient well, as a feeding tube was ultimately required to ensure adequate nutrition while healing a small pharyngeal pouch and due to the patient's discomfort with swallowing (although no frank dysphagia was noted on swallowing evaluation).

While en bloc resection of aggressive primary spine tumors is generally accepted among surgical spine oncologists, this philosophy has not been directly addressed in the pediatric literature. A handful of pediatric cases have been reported in large series, $5,19,23,31,32$ with the youngest patient recorded being 4 years of age. However, the extent of surgery in these young patients and their ultimate outcome were unclear. The successful en bloc resection of a C-1 lateral mass osteosarcoma in a 23-kg, 8-year-old patient demonstrates that the consideration of extensive multistage procedures may be warranted despite the patient's small size and young age. In this case, particular attention was paid to blood loss because of the patient's relative small blood volume. The anesthesia team aggressively managed fluids and was liberal with line placement since there was a real risk of vascular injury and the patient was mildly anemic due to preoperative chemotherapy. Furthermore, preoperative consideration was given to the patient's size. Not only did the skeletal structures need to be strong enough to allow for a complete reconstruction, but access was considered, specifically jaw-opening ability for the transoral approach. Finally, the preoperative discussion was more extensive with both patient and family, especially given the multistage nature of the procedure. While consent was ultimately obtained from the parents, the patient also provided assent to proceed.

The limitations of en bloc procedures are not yet known. Ultimately, it appears that en bloc resections may improve survival and decrease local recurrence compared with intralesional resections; however, this comes at the cost of increased morbidity associated with very challenging procedures. To this point, most discussions of limitations have centered on anatomical challenges based on tumor location. However, the age and size of the patient have not been considered. As surgical techniques continue to improve, further study of the applications of en bloc surgery to pediatric patients should be considered.

\section{Conclusions}

Neoadjuvant chemotherapy and en bloc resection are the current standard of care for osteosarcoma. While technically challenging, en bloc osteosarcoma resection should be considered in any location in the fixed or mobile spine. Furthermore, these complex procedures may be possible even in the pediatric population.

\section{References}

1. Bauer HC, Wedin R: Survival after surgery for spinal and extremity metastases. Prognostication in 241 patients. Acta Orthop Scand 66:143-146, 1995

2. Bielack SS, Wulff B, Delling G, Göbel U, Kotz R, Ritter J, et al: Osteosarcoma of the trunk treated by multimodal therapy: experience of the Cooperative Osteosarcoma study group (COSS). Med Pediatr Oncol 24:6-12, 1995

3. Bilsky MH, Boland PJ, Panageas KS, Woodruff JM, Brennan MF, Healey JH: Intralesional resection of primary and metastatic sarcoma involving the spine: outcome analysis of 59 patients. Neurosurgery 49:1277-1287, 2001

4. Bogoch ER, English E, Perrin RG, Tator CH: Successful surgical decompression of spinal extradural metastases of liposarcoma. Spine (Phila Pa 1976) 8:228-235, 1983

5. Boriani S, Biagini R: De lure F, Bertoni F, Malaguti MC, Di Fiore M, Zanoni A: En bloc resections of bone tumors of the thoracolumbar spine. A preliminary report on 29 patients. Spine (Phila Pa 1976) 21:1927-1931, 1996

6. Brennan MF: Soft tissue sarcoma: advances in understanding and management. Surgeon 3:216-223, 2005

7. Brown DA, Mallory GW, Higgins DM, Abdulaziz M, Huddleston PM, Nassr A, et al: A cost-effective method for femoral head allograft procurement for spinal arthrodesis: an alternative to commercially available allograft. Spine (Phila Pa 1976) 39:E902-E906, 2014

8. Clarke MJ, Hsu W, Suk I, McCarthy E, Black JH III, Sciubba DM, et al: Three-level en bloc spondylectomy for chordoma. Neurosurgery 68 (2 Suppl Operative):325-333, 2011

9. Clarke MJ, Mendel E, Vrionis FD: Primary spine tumors: diagnosis and treatment. Cancer Contr 21:114-123, 2014

10. Clarke MJ, Zadnick PL, Groves ML, Dasenbrock HH, Sciubba DM, Hsu W, et al: En block hemisacrectomy and internal hemipelvectomy via the posterior approach. J Neurosurg Spine 21:458-467, 2014

11. Clarke MJ, Zadnik PL, Groves ML, Sciubba DM, Witham TF, Bydon A, et al: Fusion following lateral mass reconstruction in the cervical spine. J Neurosurg Spine 22:139-150, 2015

12. Cohen ZR, Fourney DR, Marco RA, Rhines LD, Gokaslan ZL: Total cervical spondylectomy for primary osteogenic sarcoma. Case report and description of operative technique. J Neurosurg 97 (3 Suppl):386-392, 2002

13. Conlon KC, Casper ES, Brennan MF: Primary gastrointestinal sarcomas: analysis of prognostic variables. Ann Surg Oncol 2:26-31, 1995

14. DeLaney TF, Park L, Goldberg SI, Hug EB, Liebsch NJ, Munzenrider JE, et al: Radiotherapy for local control of osteosarcoma. Int J Radiat Oncol Biol Phys 61:492-498, 2005

15. Dirix LY, Vermeulen P, De Wever I, Van Oosterom AT: Soft tissue sarcoma in adults. Curr Opin Oncol 9:348-359, 1997

16. Enneking WF, Spanier SS, Goodman MA: A system for the surgical staging of musculoskeletal sarcoma. Clin Orthop Relat Res 153:106-120, 1980

17. Farhood AI, Hajdu SI, Shiu MH, Strong EW: Soft tissue sarcomas of the head and neck in adults. Am J Surg 160:365369,1990

18. Fischgrund JS, Cantor JB, Samberg LC: Malignant degeneration of a vertebral osteochondroma with epidural tumor extension: a report of the case and review of the literature. J Spinal Disord 7:86-90, 1994 
19. Fisher CG, Keynan O, Boyd MC, Dvorak MF: The surgical management of primary tumors of the spine: initial results of an ongoing prospective cohort study. Spine (Phila Pa 1976) 30:1899-1908, 2005

20. Gandolfi A, Bordi C: Primary osteosarcoma of the cervical spine causing neurological symptoms. Surg Neurol 21:441444, 1984

21. Gherlinzoni F, Picci P, Bacci G, Campanacci D: Limb sparing versus amputation in osteosarcoma. Correlation between local control, surgical margins and tumor necrosis: Istituto Rizzoli experience. Ann Oncol 3 (Suppl 2):S23-S27, 1992

22. Hollenbeck ST, Grobmyer SR, Kent KC, Brennan MF: Surgical treatment and outcomes of patients with primary inferior vena cava leiomyosarcoma. J Am Coll Surg 197:575-579, 2003

23. Kelley SP, Ashford RU, Rao AS, Dickson RA: Primary bone tumours of the spine: a 42-year survey from the Leeds Regional Bone Tumour Registry. Eur Spine J 16:405-409, 2007

24. Kraus DH, Dubner S, Harrison LB, Strong EW, Hajdu SI, Kher U, et al: Prognostic factors for recurrence and survival in head and neck soft tissue sarcomas. Cancer 74:697-702, 1994

25. Laus M, Zappoli FA, Malaguti MC, Alfonso C: Intralesional surgery of primary tumors of the anterior cervical column. Chir Organi Mov 83:43-51, 1998

26. Lefebvre G, Renaud A, Rocourt N, Cortet B, Ceugnart L, Cotten A: Primary vertebral osteosarcoma: five cases. Joint Bone Spine 80:534-537, 2013

27. Link MP, Goorin AM, Miser AW, Green AA, Pratt CB, Belasco JB, et al: The effect of adjuvant chemotherapy on relapse-free survival in patients with osteosarcoma of the extremity. N Engl J Med 314:1600-1606, 1986

28. Mankin HJ, Hornicek FJ, Rosenberg AE, Harmon DC, Gebhardt MC: Survival data for 648 patients with osteosarcoma treated at one institution. Clin Orthop Relat Res 429:286291, 2004

29. McCarter MD, Jaques DP, Brennan MF: Randomized clinical trials in soft tissue sarcoma. Surg Oncol Clin N Am 11:11-22, 2002

30. Molina CA, Ames CP, Chou D, Rhines LD, Hsieh PC, Zadnik PL, et al: Outcomes following attempted en bloc resection of cervical chordomas in the $\mathrm{C}-1$ and $\mathrm{C}-2$ region versus the subaxial region: a multiinstitutional experience. J Neurosurg Spine 21:348-356, 2014

31. Ozaki T, Flege S, Liljenqvist U, Hillmann A, Delling G, Salzer-Kuntschik M, et al: Osteosarcoma of the spine: experience of the Cooperative Osteosarcoma Study Group. Cancer 94:1069-1077, 2002

32. Rao G, Suki D, Chakrabarti I, Feiz-Erfan I, Mody MG, McCutcheon IE, et al: Surgical management of primary and metastatic sarcoma of the mobile spine. J Neurosurg Spine 9:120-128, 2008

33. Roy-Camille R, Saillant G, Bisserié M, Judet T, Hautefort E, Mamoudy P: [Total excision of thoracic vertebrae (author's transl).] Rev Chir Orthop Repar Appar Mot 67:421-430, 1981 (Fr)

34. Roy-Camille R, Saillant G, Mazel CH, Monpierre H: Total vertebrectomy as treatment of malignant tumors of the spine. Chir Organi Mov 75 (1 Suppl):94-96, 1990

35. Russo P, Brady MS, Conlon K, Hajdu SI, Fair WR, Herr HW, et al: Adult urological sarcoma. J Urol 147:1032-1037, 1992

36. Schwab JH, Antonescu CR, Athanasian EA, Boland PJ, Healey JH, Morris CD: A comparison of intramedullary and juxtacortical low-grade osteogenic sarcoma. Clin Orthop Relat Res 466:1318-1322, 2008

37. Sciubba DM, Okuno SH, Dekutoski MB, Gokaslan ZL: Ewing and osteogenic sarcoma: evidence for multidisciplinary management. Spine (Phila Pa 1976) 34 (22 Suppl):S58S68, 2009

38. Stojadinovic A, Yeh A, Brennan MF: Completely resected recurrent soft tissue sarcoma: primary anatomic site governs outcomes. J Am Coll Surg 194:436-447, 2002

39. Sundaresan N, Rosen G, Boriani S: Primary malignant tumors of the spine. Orthop Clin North Am 40:21-36, v, 2009

40. Sundaresan N, Rosen G, Huvos AG, Krol G: Combined treatment of osteosarcoma of the spine. Neurosurgery 23:714719, 1988

41. Tasdemiroglu E, Bagatur E, Ayan I, Darendeliler E, Patchell RA: Primary spinal column sarcomas. Acta Neurochir (Wien) 138:1261-1266, 1996

42. Tomita K, Kawahara N, Baba H, Tsuchiya H, Fujita T, Toribatake Y: Total en bloc spondylectomy. A new surgical technique for primary malignant vertebral tumors. Spine (Phila Pa 1976) 22:324-333, 1997

43. Tomita K, Toribatake Y, Kawahara N, Ohnari H, Kose H: Total en bloc spondylectomy and circumspinal decompression for solitary spinal metastasis. Paraplegia 32:36-46, 1994

44. Yao KC, Boriani S, Gokaslan ZL, Sundaresan N: En bloc spondylectomy for spinal metastases: a review of techniques. Neurosurg Focus 15(5):E6, 2003

\section{Disclosures}

The authors report no conflict of interest concerning the materials or methods used in this study or the findings specified in this paper.

\section{Author Contributions}

Conception and design: Clarke. Acquisition of data: all authors. Analysis and interpretation of data: Clarke. Drafting the article: Clarke. Critically revising the article: all authors. Reviewed submitted version of manuscript: all authors. Approved the final version of the manuscript on behalf of all authors: Clarke.

\section{Correspondence}

Michelle J. Clarke, Department of Neurologic Surgery, Mayo Clinic, 200 First St. SW, Rochester, MN 55905. email: clarke. michelle@mayo.edu. 